\title{
Experiences of Midlife Women and Related Co-Morbidity Issues During Menopausal Transition in Delta State, Nigeria
}

\author{
OYIBOCHA, Elizabeth Oghoteru \\ Department of Nursing Science, Delta State University, P.M.B. 1, Abraka, Delta State, Nigeria
}

\begin{abstract}
:
Naturally, midlife women transit from reproductive to non-reproductive stage of life. This transition period of life is often accompanied with gradual decline in ovarian function and it is marked with physical, psychosocial, mental and sexual changes which could last for several years. This study examined the changes of menopausal transition and their related co-morbidity issues among Delta State women.Methodology: 405 sample size midlife women were selected to participate in this study using the W.G. Cochran formula with level of statistical significance set at 0.05 . The study adopted a cross-sectional design that employed a mixed method approach. A modified MENQOL questionnaire was used to generate quantitative data and a self developed semi-structured interview guide to generate qualitative data. Reliability and validity of the instruments were tested in relation to the study through a pilot study. However, internal consistency of reliability of the MENQOL instrument subscales was checked using a Cronbach alpha test with a result of 0.832 . Generated quantitative data were analyzed using descriptive statistics while Qualitative data obtained using a tape recorder were transcribed, reported verbatim and analyzed using content analysis and triangulation methods. Hypothesis tested using multiple regression. Results: This study revealed that, vasomotor symptoms such as hot flashes and profuse sweating were frequently reported. Other findings reported were physical symptoms (decreased stamina and weight gain); sexual symptoms (altered sexual desire and dryness of the vagina) and psychosocial symptoms (poor memory and less work accompliment). Reported related co-morbidity issues include; hypertension, chest pain, broken bone (fracture), diabetes, arthritis, bone weakness (osteroporosis) and occasional malaria and typhoid fever.Conclusion: This study concluded that women in their post menopausal age experienced most of the transitional symptoms. Those who understood the transitional changes to be medically related condition rated the symptoms more significantly negative than those who viewed the symptoms as normal and gradual ageing process. Bone weakness and broken bone had strong relationship with the women's health and general well-being.
\end{abstract}

Keywords: Menopausal transition experiences; Co-morbidity issues and Midlife women.

DOI: $10.7176 / \mathrm{JHMN} / 74-06$

Publication date:May $31^{\text {st }} 2020$

\subsection{Introduction}

The term menopause originated from the Latin word 'ments' meaning 'month' and the Greek word 'pausis' meaning 'to cease' (Basavanttappa, 2011). Menopause is a physiological cessation of menstruation for twelve calendar months (Nettina, 2010). Menopausal transition phase of life is marked with endocrinological, biological and clinical symptoms which could be physical, hormonal, social, sexual and psychological. These experiences are usually accompanied with a bunch of distress.

The concept of menopausal transition used in this study has three phases; peri-menopause, menopause and post-menopause. According to the National Institute on Aging National Institutes of Health U.S. Department of Health and Human Services (2013), the menopausal transition usually has three parts; (i) Peri-menopause phase which is the beginning of the transition phase that usually commence several years before final stoppage of menstrual flow, (ii) Menopause phase marks the end of menstrual period (a twelve calendar months without menstrual flow), and (iii) Post-menopause phase immediately follows final cessation of menses and continues for the rest of the woman's life.

In another development, Murphy, Phillips, Hall and Brooks (2011) described the menopausal transition period in three stages as follows:

1. Peri-menopause stage: This stage commences around 40 years of age in women and can last up to 8 to 10 years before natural menopause begins. During this stage, there is gradual reduction in estrogen production and many women experience symptoms like hot flashes, mood swings, night sweats, irregular menses, loss of libido and vaginal dryness. However, some women still having menstrual cycles that can result in pregnancy when engaged in unprotected sexual intercourse.

2. Menopause: This is the end of menstruation stage. At this time, the ovaries function of ova production and release seizes. Diagnosis of menopause can be made when a woman has failed to menstruate for 12 consecutive months (one year). This stage is often accompanied with hot flushes, night and day sweats, loss of libido, weight gain, hair loss, anxiety, nervousness, mood swings, irritability, tiredness, forgetfulness amongst other symptoms.

3. Post-menopause: These are the years after the end of menstruation. Menopausal symptoms at this stage 
include; hot flashes are ease for most women. The women are also at risk for certain health challenges such as breast cancer, urinary tract infection, insomnia, osteoporosis, fractures, cardiovascular diseases amongst other health conditions.

Women during the menopausal transition experience a variety of symptoms which can be broadly grouped into physical, sexual, psychosocial and vasomotor complaints. (Rahman, Zainudin \& Mun, 2010 and Sembulingam \& Sembulingam, 2010). Although several studies have confirmed factors like smoking, obesity and alcohol intake as influencing the onset of menopause, other factors still exist. Examples include; socio-economic status, late menarche, multiparity, prolonged menstrual cycles and drugs like oral contraceptives (Chang, 2007; Dvornyk, 2006; Lawlor, Ebrahim \& Smith, 2003).

Physical symptoms noted include: body ache; aching in muscles and joints; lack of energy; sleeping difficulties; dry skin and decrease in physical strengths as most prevalent physical symptoms in menopause (Nusrat \& Nisar, 2009). Other noted symptoms are: dizzy spells, palpitations and weakness; irritability; headaches; lethargy; hair changes; thinning of public; axillary and head hair; stress incontinence/urinary incontinence (Sembulingam \& Sembulingam, 2010; Smeltzer, Bare, Hinkle \& Cheever, 2010; and London, Ladewig, Ball \& Binderler, 2007).

Sexual symptoms during peri-menopausal transition are usually associated with changes in normal menstrual cycles. The ovaries response to pituitary gonadotrophins (LH and FSH) decrease. Initially, it begins with shorter follicular phases (shorter menstrual cycles) with fewer ovulation, decreased progesterone production and cycle irregularity. Consequently, estrogen production ceases. (Sembulingam \& Sembulingam, 2010; Smeltzer et al, 2010; Walsh, 2002; Lathe, 2003; London et al, 2007). Nusrat and Nisar (2009) in their study reported decrease sexual desire as the most prevalent symptom during menopause. Others symptoms are decreased libido; less full and firm breasts and dyspareunia.

Psychosocial symptoms include: feeling of anxiety; forgetfulness; feeling of depression and being impatient with others (Nusrat \& Nisar, 2009); irritability (London et al, 2007; Smeltzer et al, 2010) and development of poor body image and changes in midlife women's perceived role in life as contributory factor to their low self esteem (Bloch, 2002).

Many women during this period experience a vasomotor disturbance commonly known as hot flashes (a feeling of heat arising from the chest region and radiating to the neck and face). In Europe and North America, the hot flush is reported as the most common symptom of menopause, affecting around $70 \%$ of women and persisting on average for $2-5$ years, although some $20 \%$ continue to flush into their 70 s and 80 s (Andrikoula \& Prelevic, 2009). By comparison, there are relatively unreported symptoms in Japanese populations, affecting between 518\% women (Freeman \& Sherif, 2007). Again in United States according to Gold, Sternfeld, Kelselly, Brown, Mouton and Reame (2000) in their study, $45.6 \%$ of African-American women; 35.4\% of Hispanic women; $31.2 \%$ Caucasian women; 20.5\% Chinese women and 17.6\% Japanese women reported hot flushes as a common symptom in climacteric transition. In 2006, Pakistan women reported 55\% frequency of hot flushes (Qazi, 2006). However, there variations in the nature of the symptoms among individual women and across cultures and nations.

Important morbidity issues associated with menopasual transition include: osteoporosis and fractures due to decreased estrogen levels which ordinarily help to build and maintain bones and increased risk of cardiovascular disease (Miller \& Keane, 2003; Ricci, 2013). Hence women approaching menopausal transition phase of life often present concerns about their health based on a possible family history of osteoporosis, cancer and/or heart diseases (Smeltzer et al, 2010).

Treatment during menopause transition has raised concerns for health care providers (Theroux, 2010; Writing Group for the Women's Health Initiative [WHI], 2002). This is because; such women often seek the support and assistance of the health care providers. Management of these symptoms then should be individualized as symptoms vary with every woman. However, management and prevention of the hazards requires regular exercises which help to stimulate the production of endorphins, which increase one's sense of well-being, improve circulation and help prevent osteoporosis. In addition, limitation of foods high in saturated fat and nitrites, avoiding red meat, coffee, chocolate and alcohol. The use of prescribed drugs like vitamins E, D, and the B complex, calcium gluconate or carbonate and magnesium have been found helpful (Smeltzer et al, 2010; Nettina, 2010; Copstead \& Banasik, 2005; Miller \& Keane, 2003; Walsh, 2002).

Another important form of management in women with several symptoms and/or health disorders, is the Hormonal Replacement Therapy (HRT) though it may not be suitable for all women. The main aims of the HRT are to; reduce the symptoms associated with menopausal experiences, prevent the disorders arising from the estrogen depletion and avoid causing disorders that may be common with the therapy such as endometrial and breast cancer (Walsh, 2002; Semltzer et al, 2010; Sembulingam \& Sembulingam, 2010; Nettina, 2010).

Although, World Health Organization [WHO] (1998) described quality of life (QoL) as individuals' own perception of life in the context of the culture and value systems in which they reside, natural events in life like menopause can alter the individual's quality of life and general well-being (Holms, 2005). Consequently, healthrelated quality of life (HRQoL) was viewed by Schneider, Maclennan and Feeny (2008) and Bowlings (2005) as 
a dimension of QoL that deals with the effects of physical, psychological, social and spiritual factors on the overall QoL of individuals. In other words, the QoL identifies four (4) domains (physical well-being such as sleep, social well-being such as family distress, psychological well-being such as depression and spiritual well-being such as hopelessness) that define an individual's QoL. Each of the domains is stated to act singly or in combination with the other domains and ultimately has an impact on the QoL.

Around the globe, symptoms of menopausal transition have been found to affect midlife women's health and general well-being. It is therefore clamant to address health issues arising in midlife women as they transit this crucial and necessary phase of life. Hence this study sets provide more information regarding menopausal transition experiences and its related co-morbidity (health changes) issues among midlife women.

\subsection{Alternate hypothesis}

There is a significant relationship between co-morbidity issues and health and general well-being of midlife women.

\subsection{Conceptual framework}

This study adopted the theory of unpleasant symptoms (TOUS). TOUS was developed by Lenz, Suppe, Gift, Pugh and Milligan in 1995. The theory has three major components which are:

i. $\quad$ Experienced symptoms - Symptoms experienced by individuals could occur singly or in clusters. In other words, multiple symptoms can be experienced simultaneously depending on the prevailing circumstance.

ii. Factors influencing symptoms - Factors influencing symptoms could be physical/physiological such as presence of an illness/disease; psychological such as individual's mental disturbance or mood and situational such as marital status. According to Wolkove, Dajczman, Colcone and Kreisman (1989), individuals who present with physiological factors tend to demonstrate variations in the symptoms they experience.

iii. Consequences of symptoms - Consequences of symptoms are the effects of experienced symptoms in individuals. Cluster of experienced symptoms can result in decrease health status and general wellbeing.

The concept of TOUS therefore implies that, experience of several severe symptoms could result in decreased health status, cognitive functioning, general well-being and physical performances.

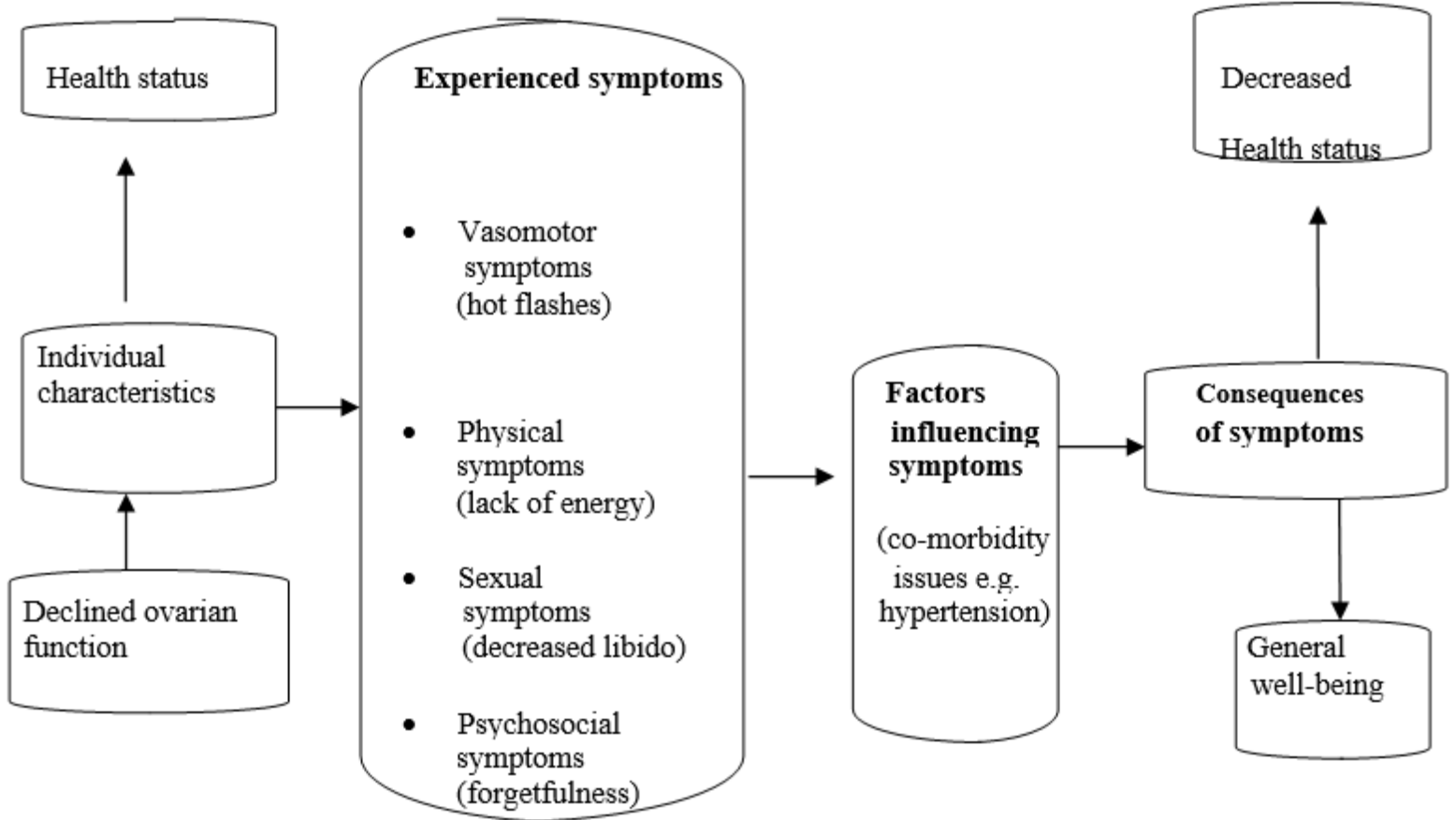

Fig. 1: Modified Lenz et al 1995 Model of Theory of Unpleasant Symptoms (TOUS)

\subsubsection{Relevance of TOUS to this study}

The conceptual framework is of great relevance while considering the three components in relation to the experienced menopausal transition symptoms.

Experienced symptoms: These can be viewed in the four domains of menopausal transition period; vasomotor symptoms such as hot flashes, profuse sweating etc; physical symptoms such as lack of energy, dry skin, sleeping difficulties etc; sexual symptoms decreased libido, dyspareunia etc and psychosocial symptoms such as feeling of 
anxiety; forgetfulness; irritability etc.

Factor influencing symptoms: Factors such as co-morbidity issues such as hypertension, diabetes, osteoporosis, fracture and their several symptoms could complicate the experienced symptoms of menopausal transition.

Consequences of symptoms: The consequences of the co-morbidity issues and their related symptoms will of course result in deterioration of the health status and general well-being of those affected.

\subsection{Methodology}

2.1. Study setting: This study was carried out in Delta State, one of the States in the South-South Geo-political zones in Nigeria. The State has three senatorial districts consisting of 25 local government areas (L.G.As) with several political wards and communities. Six out of the several communities were studied in course of this research. These communities include: Eku and Otovwodo communities in Delta Central Senatorial district; Kiagbodo and Ode-Itsekiri communities in Delta South Senatorial district and Umutu and Kwale communities in Delta North Senatorial district. In the 2006 Population and Housing Census, Delta State has a population of 4,112,445 (2,069,309 males and 2,043,136 females). (Source: The Executive Governor Delta State Government. Retrieved 2013-06-23 \& Federal Republic of Nigeria, Official gazette, No. 24, vol. 94, 2007)

2.2. Study design: This study was a cross-sectional descriptive study that employed a mixed method approach (quantitative and qualitative data collection).

2.3. Target population: The target population consists of 306,470 midlife women within the age of 45 to 60 years. Inclusion criteria who are within the age of 45 to 60 years and who are not in any hormonal therapy such as hormonal replacement therapy (HRT).

2.4. Sample size determination: The sample size was calculated using the W.G. Cochran's formula: $\mathrm{n} 0=\frac{(\mathrm{t})^{2}}{(\mathrm{~d})^{2}} \mathrm{x}(\mathrm{p})(\mathrm{q})$

Where:

$\mathrm{n} 0=$ desired sample size (if the target population is $>10,000$ )

$\mathrm{t}=$ the value for the selected alpha level (1.96) (confidence level for $95 \%$ confidence)

$\mathrm{p}=$ estimated proportion of attributes that are present in the target population

$\mathrm{q}=1-\mathrm{p}$

$\mathrm{d}=$ the level of statistical significance set $(0.05)$ (degree of variability that is, proportion)

Since the approximate population of women in the climacteric period in the study area is about 306,470 .

The sample size was calculated thus:

$\mathrm{n} 0=\frac{(1.96)^{2} \times(0.5)(1-0.5)}{(0.05)^{2}}$

$$
(0.05)^{2}
$$

$=\underline{3.8416} \times \underline{x} \underline{(0.5)(0.5)}$

0.0025

$=\underline{3.8416} \times \underline{0.25}$

0.0025

$=\underline{0.9604}$

0.0025

$=384.16$ (approx. 400).

The final sample size was 420 including an attrition rate of $5 \%$.

2.5. Sampling technique: The multistage sampling technique was employed in this study. The procedure involved three (3) stages:

First stage: It involved simple random sampling technique used to select 2 L.G.As in each of the 3 senatorial districts (total of 6 L.G.As selected).

Second stage: A simple random sampling technique was used to select 1 ward in each of the 6 selected L.G.As. And 1 community in each of the selected wards. A total of 6 communities were then selected.

Third stage: This involved the use of a systematic random sampling technique to select 90 households from each of the selected communities with sampling interval of 5. One subject per household was selected from each of the 90 households in each community using purposive sampling technique until the sample size was reached.

2.6. Research instrument: A modified Menopause-Specific Quality of Life (MENQoL) proposed by Hilditch, Lewis, Peter, Van Maris, Ross, Franssen, Guyatt, Norton, and Dunn, (1996) at the University of Toronto, North York, Ontario. The modified MENQoL is made up of two sections. Section A elicits data personal characteristics and co-morbidity issues. Section B worded in a 7-point likert scale comprises of 29 items with four domains: Vasomotor domain (items 1 - 3), Psychosocial domain (items 4 - 10), Physical domain (items 11 - 26) and Sexual domain (items 27 - 29), all were used to assess the degree of menopausal symptoms as experienced over the last month and to generate quantitative data. The second instrument is a self developed semi-structured interview guide which consists of 15 open-ended questions on menopausal symptoms and 
their effect on the women's health and general well-being that allowed for further probing as desirable. This was used to generate qualitative information.

2.7. Instrument reliability and validity: A pilot study was conducted to test the instruments at another community within the State (Owhelogbo community). Forty-four midlife women within the age of $45-60$ years who were conveniently selected participated in the pilot study and three women interviewed to test the reliability of the instruments and their applicability in Nigeria situation. However, the internal consistency of reliability of the MENQoL instrument subscales was checked using a cronbach alpha test with a result of 0.832 . While the validity was tested using face and content criteria. The instruments were also given to experts in Nursing, Sociology and Psychology for possible modification of some of the items and to assess the relevance to the subject matter, its scope and coverage.

2.8. Method of date collection: The questionnaire was administered to the subjects on one-on-one contact, same with the in-depth interview sessions of 15 subjects with the assistance of three research assistants. The assistants who are registered nurse/midwife were trained for two days. Data were generated between January and May, 2015. A total of 420 questionnaires were administered, but 405 were retrieved making a $96.4 \%$ return. Interview sessions were recorded with a tape recorder.

2.9. Method of data analysis: Generated quantitative data were analyzed using statistical package for social sciences (SPSS) version 20.0. Same presented using descriptive statistics in form of frequency distribution and percentages. While inferential statistics (multiple regression) was used to test the hypothesis that was formulated. A confidence level (p-value) of 0.05 was considered significant. Qualitative data obtained using a tape recorder were transcribed, reported verbatim and analyzed using content analysis and triangulation methods

2.10. Ethical consideration A Gate Keeper's permits were obtained from the heads of the six studied communities. In addition, a verbal informed consent was obtained from the all participants. Confidentiality and the right of refusal of participants were equally stressed. Pseudonym was adopted when presenting the findings to maintain the participants' anonymity.

2.11. Limitations: The limitations of this study were inclusion of only heterosexual midlife women and perceived biased responses of the subjects to questions concerning their sexual life.

\subsection{Results}

\subsection{Socio demographic variables of respondents}

Respondents' socio demographic variables show that thirty-Eight (38\%) of the respondents were between the ages of 55-60 years. Majority of them were married (67.9\%). More than half of the respondents have between 1-5 children $(69.4 \%)$. A little above half of the respondents had tertiary education as their highest educational level attained $(52.3 \%)$ and forty seven percent were employed by the government.

Table 1: Socio demographic variables of the respondents

\begin{tabular}{|l|l|l|}
\hline Variables & Frequency N=405 & Percentage 100\% \\
\hline Age (in grouped years) & \multirow{2}{*}{125} & 30.9 \\
\hline $45-49$ & 126 & 31.1 \\
\hline $50-54$ & 154 & 38.0 \\
\hline $55-60$ & 13 & 3.2 \\
\hline Marital status & 13 & 67.9 \\
\hline Single & 275 & 12.8 \\
\hline Married & 52 & 16.0 \\
\hline Separated /Divorced & 65 & 69.4 \\
\hline Widow & 281 & 29.6 \\
\hline Number of children & 28 & 1.0 \\
\hline $1-5$ & 120 & 7.7 \\
\hline $6-10$ & 4 & 11.1 \\
\hline 11 and above & 31 & 28.9 \\
\hline Highest Education qualification & 45 & 52.3 \\
\hline No formal education & 117 & \\
\hline Primary education & 212 & \\
\hline Secondary education & & \\
\hline Tertiary education & & \\
\hline
\end{tabular}




\begin{tabular}{|l|l|l|}
\hline Variables & Frequency N=405 & Percentage 100\% \\
\hline Occupation & 183 & 45.2 \\
\hline Self employed & 191 & 47.2 \\
\hline Government \& private employed & 20 & 4.9 \\
\hline Unemployed & 11 & 2.7 \\
\hline Retirees & & \\
\hline
\end{tabular}

\subsection{Co-morbidity issues of respondents}

A few of the respondents (7.9\%) have history of cardiovascular/heart disease out of which $21.8 \%, \mathrm{n}=32$ suffered from chest pain occasionally for the past 5-15 years and $78.2 \%, \mathrm{n}=32$ have hypertension for the past 5-10 years. Only $9.1 \%$ of the respondents have history of bone weakness out of which $94.6 \%, \mathrm{n}=37$ said the bone weakness started few years ago (1-6 years) and the remaining 5.4\%, $\mathrm{n}=37$ said that it started less than 12 months ago. Also, $5.2 \%$ have history of broken bone which $85.7 \%, \mathrm{n}=21$ affirmed that it started since $1-5$ years ago and $14.3 \%, \mathrm{n}=21$ said that it started less than 12 months ago. $10.4 \%$ of the respondents presented with diabetes mellitus out of which $16.7 \%, \mathrm{n}=42$ have been experiencing it less than 12 months ago and $83.3 \%, \mathrm{n}=42$ more than 5 years ago. $9.6 \%$ of them had other ailments such as malaria, typhoid fever and arthritis out of which $64.1 \%, \mathrm{n}=39$ had the ailment for less than 12 months ago and $35.9 \%, \mathrm{n}=39$ for more than 3 years ago.

Table 2: Co-morbidities issues reported by the respondents

\begin{tabular}{|l|l|}
\hline Variables & Frequency (\%) \\
\hline Any history of cardiovascular/heart disease & $32(7.9)$ \\
\hline If yes, state the disease condition and when it started & $7(21.8)$ \\
\hline Chest pain occasionally (5-15 years ago) & $25(78.2)$ \\
\hline Hypertension (5-10 years ago) & $\mathbf{3 2}(\mathbf{1 0 0})$ \\
\hline Total & $37(9.1)$ \\
\hline Any history of bone weakness (osteoporosis) & \\
\hline If yes, when did it start? & $2(5.4)$ \\
\hline Few months ago ( 12 months) & $35(94.6)$ \\
\hline Few years ago(1-6 years) & $\mathbf{3 7 ( 1 0 0 )}$ \\
\hline Total & $21(5.2)$ \\
\hline Any history of broken bone (fracture) & \\
\hline If yes, when did it start? & $3(14.3)$ \\
\hline Few months ago ( 12 months) & $18(85.7)$ \\
\hline Few years ago (1-5 years) & $\mathbf{2 1 ~ ( 1 0 0 )}$ \\
\hline Total & $42(10.4)$ \\
\hline Any history of diabetes mellitus? & \\
\hline If yes, when did it start? & $7(16.7)$ \\
\hline Few month ago ( 12 months) & $35(83.3)$ \\
\hline Few years ago(1-6 years) & $\mathbf{4 2 ( 1 0 0 )}$ \\
\hline Total & $39(9.6)$ \\
\hline Any other sickness? (malaria, typhoid and arthritis) & $25(64.1)$ \\
\hline If yes, when did it start? & $14(35.9)$ \\
\hline Few months ago ( 12 months) & $\mathbf{3 9}(\mathbf{1 0 0})$ \\
\hline Few years ago(1-6 years) & \\
\hline Total & \\
\hline & \\
\hline
\end{tabular}

\subsection{Menopausal transition experiences of the respondents}

In vasomotor domain, $67.9 \%$ of the respondents sweat profusely during the day; $66.9 \%$ sweat at night and $62.2 \%$ experienced hot flushes. Women in the postmenopausal age were mostly affected.

From the in-depth interview conducted these are some of the responses from respondents:

"I feel internal heat a lot both day and night, so when people complain of

cold, I laugh at them. Again, the heat and sweating always make me to

change my cloth frequently and bath frequently to avoid body odour."

(Mrs. A.V., 57 years with five children).

"I am always sweating at night and during the day. Also, hotness of the 
body internally." (Mrs. J.M., 59 years with five children).

In psychosocial domain, $67.7 \%$ of the respondents were accomplishing less work than before; $57.0 \%$ experienced poor memory; $52.6 \%$ had feeling of being anxious or nervous; almost half of the respondents $(49.9 \%)$ felt depressed; $48.4 \%$ were satisfied with their personal life; $46.9 \%$ had feeling of wanting to be alone while $43.3 \%$ were being impatient with other people. Again women in the postmenopausal age were mostly affected.

From the in-depth interview conducted, below are some of the respondent's responses:

"I feel dull sometimes, I am not smart again, I forget a lot, I have to write down in a diary to remember things. The forgetfulness, as a teacher I have to read over and over before remembering. Even when I am in class teaching, I sometimes miss track and gradually find my way back to what I am teaching. In addition, before this time, I use to be very impatient with people, but now I have learnt to tolerate people and I am more patient now." (Mrs. O.E.A., 58 years with three children).

"Forgetfulness, not remembering where I keep things sometimes. I also experience loss of hair on my head. I also have good relationship with those around me in fact, I used to be an extrovert, but presently, I feel like staying alone and I am more reserved now."

(Mrs. E.J.E., 48 years with six children).

In the physical domain, majority of the respondents representing $75.1 \%$ reported decrease in stamina; $71.1 \%$ had feeling of lack of energy; $65.7 \%$ experienced decrease in physical strength; $64.4 \%$ had difficulty sleeping while $60.5 \%$ had weight gain. $59.5 \%$ of the respondents had aching in their muscle and joint; $58.8 \%$ had feeling of being tired or worn out; $56.0 \%$ had occurrence of drying skin and $51.6 \%$ had aches in the back of their head and neck. Less than half of the respondents (44.4\%) experienced changes in appearance; $40.7 \%$ experienced low backache and $38.0 \%$ experienced frequent urination. Few of the respondents $(32.1 \%)$ had bloated feeling and $(31.1 \%)$ reported increased facial hair, texture or tone of skin. Only $26.0 \%$ of them had involuntary urinated when laughing or coughing while $18.5 \%$ reported flatulence (wind) or gas pain. Postmenopausal women gave most of these reports.

In addition, below are some of the responses from the in-depth interview conducted: "I feel tired easily and I am angry because I don't like asking for help when I am doing certain things, but now I have to ask for help." (Mrs. G.C., 49 years with six children).

"The changes have affected by life style because I can't do things as before..." (Mrs. C.B.N., 59 years with two children)

"Tiredness, body weakness, heaviness of the body, increase in my weight, dryness of my skin and especially my vagina. These I have been experiencing with the changes.” (Mrs. J.M. 59 years with five children).

While in the sexual domain, a good number of the respondents $(71.6 \%)$ experienced changes in their sexual desire; $66.9 \%$ experienced dryness in vaginal during intercourse and $53.8 \%$ tried to avoid intimacy. Majority of these symptoms were reported by women in the menopause phase of life.

From the in-depth interview conducted these are some of the responses from respondents:

"My sexual life is not as before. I don't have any strong desire for sex, I just force myself to please my husband." (Mrs. O.E.A., 58 years with three children).

"My interest for love making is dead; I don't have any desire for sex and my libido is low. In fact, I can't remember love making any more and I don't even have power for it. In fact, the changes killed my sexual life." (Mrs. G.C., 49 years with six children).

"As for my sexual life, I am usually not interested again because I feel pain during love making because of the dry vagina." (Mrs. P.H.O., 54 years with two children). 
Table 3: Menopausal transition symptoms experienced by respondents

\begin{tabular}{|c|c|c|c|c|}
\hline \multirow[t]{2}{*}{ Variables } & \multicolumn{3}{|c|}{ Frequency (\%) } & \multirow[t]{2}{*}{ Total (\%) } \\
\hline & Peri-menopause & menopause & Post-menopause & \\
\hline Vasomotor domain & \multirow[b]{2}{*}{$85(21.0)$} & \multirow[b]{2}{*}{$86(21.3)$} & \multirow[b]{2}{*}{$104(25.7)$} & \multirow[b]{2}{*}{$275(67.9)$} \\
\hline 1. Sweating during the day & & & & \\
\hline 2. Night sweat & $78(19.3)$ & $78(19.3)$ & $96(23.6)$ & $271(66.9)$ \\
\hline 3. Hot flushes & $84(20.7)$ & $84(20.7)$ & $103(25.5)$ & $252(62.2)$ \\
\hline \multicolumn{5}{|l|}{ Psychosocial domain } \\
\hline 4. Accomplishing less than I used to & $85(21.0)$ & $85(21.0)$ & $104(25.7)$ & $274(67.7$ \\
\hline 5. Experiencing poor memory & $71(17.5)$ & $72(17.8)$ & $88(21.7)$ & $231(57.0)$ \\
\hline 6. Feeling anxious or nervous & $66(16.3)$ & $66(16.3)$ & $81(20.0)$ & $213(52.6)$ \\
\hline 7. Feeling depressed, down or blue & $62(15.3)$ & $63(15.6)$ & $77(19.0)$ & $202(49.9)$ \\
\hline $\begin{array}{l}\text { 8. Being dissatisfied with my personal } \\
\text { life }\end{array}$ & $61(15.1)$ & $61(15.1)$ & $74(18.2)$ & $196(48.4)$ \\
\hline 9. Feelings of wanting to be alone & $58(14.3)$ & $59(14.6)$ & $73(18.0)$ & $190(46.9)$ \\
\hline 10. Being impatient with other people & $55(13.6)$ & $55(13.6)$ & $67(16.5)$ & $177(43.7)$ \\
\hline \multicolumn{5}{|l|}{ Physical domain } \\
\hline 11. Decrease in stamina & $94(23.2)$ & $95(23.5)$ & $115(28.4)$ & $304(75.1)$ \\
\hline 12. Feeling a lack of energy & $89(22.0)$ & $90(22.2)$ & $109(26.9)$ & $288(71.1)$ \\
\hline 13. Decrease in physical strength & $82(20.2)$ & $83(20.5)$ & $101(25.0)$ & $266(65.7)$ \\
\hline 14. Difficulty sleeping & $81(20.0)$ & $81(20.0)$ & $99(24.4)$ & $261(64.4)$ \\
\hline 15. Weight gain & $76(18.8)$ & $76(18.8)$ & $93(22.9)$ & $245(60.5)$ \\
\hline 16. Aching in muscle \& joints & $74(18.3)$ & $75(18.5)$ & $92(22.7)$ & $241(59.5)$ \\
\hline 17. Feeling tired or worn out & $74(18.3)$ & $74(18.3)$ & $90(22.2)$ & $238(58.8)$ \\
\hline 18. Drying skin & $70(17.3)$ & $71(17.5)$ & $86(21.2)$ & $227(56.0)$ \\
\hline 19. Aches in back of neck or head & $65(16.0)$ & $65(16.0)$ & $79(19.6)$ & $209(51.6)$ \\
\hline $\begin{array}{l}\text { 20. Changes in appearance, texture or } \\
\text { tone of your skin }\end{array}$ & $56(13.8)$ & $56(13.8)$ & $68(16.8)$ & $180(44.4)$ \\
\hline 21. Low backache & $51(12.6)$ & $48(11.8)$ & $62(15.3)$ & $165(40.7)$ \\
\hline 22. Frequent urination & $47(11.6)$ & $41(10.1)$ & $59(14.6)$ & $154(38.0)$ \\
\hline 23. Feeling bloated & $40(9.9)$ & $39(9.6)$ & $49(12.1)$ & $130(32.1)$ \\
\hline 24. Increased facial hair & $39(9.6)$ & $33(8.1)$ & $48(11.9)$ & $126(31.1)$ \\
\hline $\begin{array}{l}\text { 25. Involuntary urination when laughing } \\
\text { or coughing }\end{array}$ & $32(8.0)$ & $52(12.8)$ & $40(9.9)$ & $105(26.0)$ \\
\hline 26. Flatulence (wind) or gas pains & $23(5.7)$ & $23(5.7)$ & $29(7.1)$ & $75(18.5)$ \\
\hline \multicolumn{5}{|l|}{ Sexual domain } \\
\hline 27. Change in your sexual desire & $90(22.2)$ & $108(27.0)$ & $91(22.4)$ & $290(71.6)$ \\
\hline 28. Vaginal dryness during intercourse & $83(20.5)$ & $103(25.4)$ & $85(21.0)$ & $271(66.9)$ \\
\hline 29. Avoiding intimacy & $67(16.5)$ & $83(20.5)$ & $68(16.8)$ & $218(53.8)$ \\
\hline
\end{tabular}

\subsection{Some of the verbal responses of the respondents to the in-depth interview}

“... at 47 years when my menses stopped finally" (Mrs. O.E.A., 58 years with three children).

"Sometimes I feel internal heat and sometimes cold" (Mrs. O.E.A., 58 years with three children).

"At 55 years of age my menses stopped flowing" (Mrs. C.B.N., 59 years with two children).

"... the heat and sweating always make me to change my clothes frequently and I bath frequently to avoid body odour" (Mrs. A.V, 57 years with five children).

"My sexual life is not as before. I don't have any strong desire for sex, I just force myself to please my husband" (Mrs. O.E.A., 58 years with three children)

"I forget a lot nowadays and my memory is not sharp as before" (Mrs. A.V., 57 years with five children).

"My love making is no go area, because I feel pains a lot" (Mrs. J.M., 59 years with five children).

"I feel dull sometimes, I am not smart again, I forget a lot, I have to write down in a diary to remember things" (Mrs. O.E.A., 58 years with three children). 
"Forgetfulness, not remembering where I keep things sometimes. I also experience loss of hair on my head" (Mrs. E.J.E., 48 years with six children).

"I do experience vaginal dryness and lack of sexual desire. I can remain like that for two to three months" (Mrs. E.J.E., 48 years with six children).

"Since these changes are normal, I will say that my life is a bit satisfying by the grace of God" (Mrs. J.M., 59 years with five children).

"I don't really like these changes in my body because, for marriage to be strong and sweet, one need to be sexually active” (Mrs. E.J.E., 48 years with six children).

"I see the changes as a normal thing in life" (Mrs. O.E.A., 58 years with three children).

"The changes have really caused me arthritis, hypertension and insomnia" (Mrs. E.J.E., 48 years with six children).

"I think my work have not been affected in any way with the changes, because I can still do things normally like before” (Mrs. M.O., 51 years with four children).

"I feel the changes are normal for every woman" (Mrs M.O., 51 years with four children).

"Because of the changes when I was 54 years old, I fell and broke my lower right leg which is still affecting my movement till today” (Mrs. C.B.N., 59 years with two children).

"... changes in my thinking ability, forgetfulness, irritability and restlessness" (Mrs. J.M., 59 years with five children).

"I feel internal heat a lot both day and night, so when people complain of cold, I laugh at them" (Mrs. A.V., 57 years with five children).

... the changes caused me high blood pressure and hypertension which is affecting my eyes today. Now I can't read without wearing eye glass" (Mrs. G.C., 49 years with six children).

"I see the changes as normal because it is the will of God and life is in stages" (Mrs. C.B.N., 59 years with two children).

3.5. Alternate hypothesis: There is a significant relationship between co-morbidity issues and health and general well-being of midlife women.

Table 4: Qualitative Responses of the respondents on their health and general well-being and symptoms of menopausal transition

\begin{tabular}{|l|l|}
\hline Variables & Frequency (N) \\
\hline Excessive sweating (day and night) & +++ \\
\hline Internal heat (hot flushes) & ++ \\
\hline Feeling of tiredness & + \\
\hline Forgetfulness & +++ \\
\hline Reduction in physical strength and energy & +++ \\
\hline Feeling of being left alone & + \\
\hline Skin dryness & + \\
\hline Loss of hair & + \\
\hline Vagina dryness & +++ \\
\hline Lack of sexual desire & +++ \\
\hline Co-morbidity issues & ++ \\
\hline Need to seek for medical help with symptoms & + \\
\hline Being satisfied with life with symptoms & +++ \\
\hline Being unsatisfied with life with symptoms & + \\
\hline $\begin{array}{l}\text { Key } \\
+\quad \text { least reported }\end{array}$ & +++ most reported \\
\hline
\end{tabular}

\subsection{Alternate hypothesis}

Multiple regression analysis to determine the correlation between co-morbidity issues and health and general wellbeing of the women during menopausal transition. From the analysis, R $18.0 \%$ is the correlation between the dependent variable (health and general well-being) and the independent variable (co-morbidity issues). While $\mathrm{R}^{2}$ $35.0 \%$ is the variation that was explained by the independent variable. Therefore, model were statistically significant $(\mathrm{F}=2.285, \mathrm{df}=6, \mathrm{p}>0.05)$ thus, there is significant relationship between co-morbidity issues in midlife women and their health and general well-being. Diabetes mellitus with 0.059 was the best predictor of their health and general well-being followed by cardiovascular diseases $\quad-0.018$; depression $\quad-0.041$; broken bone (fracture) $\quad-0.102$; bone weakness $\quad-0.109$ and other sicknesses like malaria, typhoid fever, asthma $\quad-0.61$. The alternate hypothesis is therefore accepted. 
Table 5: Multiple regression analysis on co-morbidity issues and health and general well-being of the respondents

\section{Model Summary}

\begin{tabular}{|l|c|c|c|c|l|l|}
\hline \multirow{2}{*}{$\begin{array}{l}\text { Model (Independent } \\
\text { variables) }\end{array}$} & \multicolumn{2}{|c|}{$\begin{array}{c}\text { Unstandardized } \\
\text { coefficients }\end{array}$} & $\begin{array}{l}\text { Standardized } \\
\text { Coefficients }\end{array}$ & T & Sig & Remark \\
\cline { 2 - 7 } & Beta ( ) & Std error & Beta ( ) & & & \\
\hline Constant & 50.333 & 0.813 & & 61.895 & 0.000 & \\
\hline $\begin{array}{l}\text { Cardiovascular/heart } \\
\text { diseases }\end{array}$ & 0.880 & 2.502 & -0.018 & 0.352 & 0.725 & NS \\
\hline $\begin{array}{l}\text { Bone weakness } \\
\text { (osteoporosis ) }\end{array}$ & 4.927 & 2.371 & -0.109 & 2.078 & 0.038 & $\mathrm{~S}$ \\
\hline Broken bone (fracture) & 6.018 & 3.090 & -0.102 & 1.948 & 0.05 & $\mathrm{~S}$ \\
\hline Spirit/mood (depression) & 1.569 & 2.027 & -0.041 & -.774 & 0.439 & $\mathrm{NS}$ \\
\hline Diabetes mellitus & 3.308 & 2.947 & 0.059 & 1.123 & 0.262 & $\mathrm{NS}$ \\
\hline Others sickness & 2.061 & 1.732 & -0.61 & -1.190 & 0.235 & $\mathrm{NS}$ \\
\hline
\end{tabular}

F statistics $=2.285 ; \quad \mathrm{P}=0.035 ; \mathrm{R}=0.187 ; \mathrm{R}^{2}=0.035 ; \mathrm{R}^{2}(\operatorname{adj})=0.020 ; \quad$ Std. Error of the estimate $=13.0121$; Regression=2320.813; df=6; Mean $^{2}=386.802 ;$ Residual=63831.997; df=377; Mean $^{2}=169.316 ;$ Total=66152.810; $\mathrm{df}=383$.

\subsection{Discussion}

It a natural phenomenon for all women to transit from reproductive to non reproductive stage of life. These experiences often bring with them issues related to their health status, disease prevention and management.

\section{a. Vasomotor symptoms}

Thermoregulation related (vasomotor) symptoms particularly hot flushes and day and night sweats are the most common that affect the women's health and generally well-being especially women in postmenopausal phase. These findings agree with that of Pakistan women (Nusrat \& Nisar, 2009) and Turkish women (Ayranci, Orsal, Orsal, Arslan \& Emeksiz, 2010). Also, hot flushes in Pakistan (Qazi, 2006). Though disagree with findings among Nigerian women in Kwara State (Saka, Saka, Jimoh \& Abdulraheem, 2012) and United States African-American, Hispanic, Caucasians, Japanese and Chinese women (Gold et al, 2000). However, according to Freeman and Sheriff (2007), prevalence of such symptoms varies according to ethnic and cultural background with a range of 18 to $46 \%$. There is a further confirmation by two subjects in the qualitative data "I feel internal heat a lot both day and night, so when people complain of cold, I laugh at them. Again, the heat and sweating always make me to change my cloth frequently and bath frequently to avoid body odour." (Mrs. A.V., 57 years with five children). "I am always sweating at night and during the day. Also, hotness of the body internally." (Mrs. J.M., 59 years with five children).

\section{b. Psychosocial symptoms}

Postmenopausal women reported majority of psychosocial symptoms such as poor memory and less work accompliment. These finding are consistent with the findings among Turkish women (Ayranci et al, 2010). Average feelings of depression and anxiousness were reported in this study. Same level of anxiousness was recorded among Pakistan women with lesser feelings of depression (Nusrat \& Nisar, 2009), but Turkish women reported very high frequency of nervousness/anxiousness (Ayranci et al, 2010). On being satisfied with their personal life, feeling of wanting to be alone and being impatient with other people were near averagely recorded in this study. However in 2009, Nusrat and Nisar study amongst Pakistan women confirmed high frequency of being impatience with others. This is further confirmed by a response in qualitative data "Forgetfulness, not remembering where I keep things sometimes. I also experience loss of hair on my head. I also have good relationship with those around me in fact, I used to be an extrovert, but presently, I feel like staying alone and I am more reserved now" (Mrs. E.J.E., 48 years with six children).

\section{c. Physical symptoms}

As regards physical symptoms among the respondents, a good number of the postmenopausal women reported feeling of lack of energy, decrease in stamina, increase in weight, difficulty sleeping, aching muscles and joints, feeling of being tired or worn out and occurrence of drying skin. Similar reports were noted among Malaysian 
women who reported most cases of aching muscles and joints and lack of energy (Syed et al, 2009), high frequency of muscle-joint pains amongst Indian women (Arounassalame, 2013). Pakistan women equally reported high frequency of aching muscles and joints, sleeping difficulties, lack of energy, decrease in physical strength, feeling of tiredness and drying skin (Nusrat \& Nisar, 2009). The submission of two subjects in the qualitative data are in congruence with these reports; "The changes have affected by life style because I can't do things as before..." (Mrs. C.B.N., 59 years with two children). "Tiredness, body weakness, heaviness of the body, increase in my weight, dryness of my skin and especially my vagina. These I have been experiencing with the changes." (Mrs. J.M. 59 years with five children). A little below average reports of changes in appearance, texture or tone of skin and low backache were revealed in this study. These symptoms were parallel among Pakistan women (Nusrat \& Nisar, 2009), India women (Arounassalame, 2013), Malaysian women (Syed, Lee, Awi, Mallik, \& Md Haizal, 2009) and Turkish women (Ayranci et al, 2010) with high frequency of low backache. Little records of frequent urination, bloated feeling and increased facial hair were noted in this study. These findings were supported with record among Indian women with very few facial hair increase, very scanty reports of involuntary urinate when laughing or coughing and flatulence (wind) or gas pain (Arounassalame, 2013).

\section{d. Sexual symptoms}

In this study, menopausal women reported high frequency of sexual symptoms such as changes in sexual desire, dryness in vaginal during intercourse and average reports of trying to avoid intimacy. Edo State women of Nigeria, specifically, Benin City women reported a similar finding of being no longer sexually active (Ande, Omu, Andel \& Olaguji, 2008). In another report by Syed et al (2009), Malaysia women recorded a near average cases of vaginal dryness, Pakistan women reduced sexual desire and avoiding intimacy (Nusrat \& Nisar, 2009). While India women scanty cases of feeling of dryness during intimacy (Arounassalame, 2013). This is further affirmed by some subjects in the qualitative data; "I do experience vaginal dryness and lack of sexual desire. I can remain like that without sex for two to three months. I don't really like these changes in my body because, for marriage to be strong and sweet, one needs to be sexually active" (Mrs. E.J.E., 58 years with six children). "My interest for love making is dead; I don't have any desire for sex and my libido is low. In fact, I can't remember love making any more and I don't even have power for it. In fact, the changes killed my sexual life" (Mrs. G.C., 49 years with six children). "As for my sexual life, I am usually not interested again because I feel pain during love making because of the dry vagina” (Mrs. P.H.O., 54 years with two children).

e. Menopausal symptoms and the women' health and well-being

Findings of this study revealed that post-menopausal women were mainly affected by the transitional changes especially in the vasomotor, psychosocial and physical domains. While women in menopausal phase of life recorded majority of the sexual symptoms. Even with these findings, the women's health and general well-being was not affected. One possible explanation for this may be due to their genetic makeup, psychological, religious and cultural factors which probably shaped their perception. This however, can be attributed to the high value placed on female independence in the women's culture and greater exposure within their family groups, religious groups and friends as regards the realities of menopausal transition and the ageing process. This is further confirmed by the responses of some of the subjects in the qualitative data; "I can say that my general well being is very okay and I am very satisfied with my life at the moment" (Mrs. M.O., 51 years with four children). "I am very satisfied with my life" (Mrs. U.S.U., 47 years with four children). "My life style is very okay and I am very satisfied with my life right now” (Mrs. P.H.O., 54 years with two children). In contrary to this study's findings, only a few percent of Finnish middle-aged women demonstrated an excellent quality of life at baseline and a higher degree of deterioration which they attributed to decreased physical activities and increased weight gain (Moilanen, Aalto, Raitanen, Hemminki, Aro \& Luoto, 2010). A near average rating of very good/good health status among Turkish women (Ayranci et al, 2010). Arounassalame (2013) study concluded that menopause related symptoms had a negative effect on quality of life of India women, Pakistan women (Nusrat \& Nisar, 2009) and Malaysian women (Syed et al, 2009). Again, Ferrand and colleagues in 2013 revealed a significantly lower quality of life among Tunisian women when they compared quality of life between Tunisian and French women. This they explained by levels of national wealth, cultural constraints, human development, social and gender inequality.

\section{f. Relationship between co-morbidity issues and the women' health and well-being}

This study further revealed a significant relationship between co-morbidity issues in the midlife women and their health and general well-being with diabetes mellitus ( 0.059$)$ as the best predictor and other sicknesses like malaria, typhoid fever, arthritis $(-0.61)$ as the least predictor. The main co-morbidity issues reported were diabetes mellitus and cardiovascular diseases (hypertension and chest pain), malaria, typhoid fever and arthritis. This finding is supported by Ayranci et al (2010) who submitted that rheumatic arthritis, diabetes mellitus and hypertension were the most common co-morbidity conditions among Turkish women. Presence of co-morbidity is one of the major determinants of decline in health and well-being hence Baiardi et al (2002) posited that comorbidity issues such as diabetic mellitus and cardiovascular diseases has been associated with low quality of life. The in-depth interview revealed the following most reported co-morbidity issues; diabetes mellitus and cardiovascular diseases (hypertension and chest pain). Others were arthritis, malaria and typhoid fever. Even with 
the symptoms of menopausal transition symptoms and co-morbidity issues, the subjects were still satisfied with the quality of their lives.

\subsection{Conclusion}

This study demonstrated that although the midlife women in Delta State did experienced negative symptoms coupled with a number of co-morbidity issues during the menopausal transition period, their health and general well-being were not compromised. This is because; they have diverse views about the experiences which can be attributed to the general perception of the women towards ageing and its associated changes, genetic, cultural background and religious factors. Therefore, the paradigm within which the women considered menopausal transition influences the way they viewed it. Women who considered the transitional period as a medical condition rated it significantly negative than those who viewed it as a normal life process. This study also established that bone weakness and broken bone had strong relationship with the women's health and general well-being.

\subsection{Recommendations}

Having examined the findings of this study carefully, the following recommendations were made:

1. General assessment of the health status and well-being of women before transiting menopausal period should be encouraged as it would provide an appropriate basis for handling and managing changes associated with the transition period.

2. Efforts should be made to reduce the effects of those factors that can be modified and managed such as co-morbidity issues so as to improve the health and general well-being of midlife women through regular medical checkups.

\section{References}

[1] Ande, A.B., Omu, O.P., Andel, O.O. \& Olaguji, N.B. (2008). Features and Perceptions of Menopausal Women in Benin City, Nigeria. Annals of African Medicine, 10: 330-333.

[2] Andrikoula, M. \& Prelevic, G. (2009). Menopausal Hot Flushes Revisited. Climacteric: The Journal of The International Menopause Society, 12(1):3-15. doi:10.1080/13697130802556296

[3] Arounassalame, B. (2013). The Quality of Life during and after Menopause among rural women. J Clin Diagn Res, 7(1): 135 - 139. doi:10.7860/JCDR/2012/4910.2688.

[4] Ayranci, U, Orsal, O, Orsal, O, Arslan \& Emeksiz, D.F (2010). Menopause status and attitude in a Turkish midlife female population: An epidemiological study. BMC Women's Health, 10(1) doi:10.1186/1472-6874$10-$

[5] Baiardi, F., Delgli-Esposti, E., Cocchi, R., Fabbri, A., Sturani, A., Valpiani, G., et al (2002). Effects of clinical and individual variables on quality of life in chronic renal failure patients. J Nephrol, 15: 61-67.

[6] Basavanthappa, B.T. (2011). Essentials of Midwifery and Obstetrical Nursing. India: Jaypee Brothers Publishers (P) Ltd.

[7] Bloch, A. (2002). Self-awareness during the menopause. Maturitas, 41: $61-68$.

[8] Bowlings, A. (2005.) Measuring Health. A Review of Quality of Life Measurement Scales. $3^{\text {rd }}$. ed. Buckingham: Open University Press.

[9] Chang, S.H., Kim, C.S., Lee, K.S., Kim, H., Yim, S.V., Lim, Y.L. \& Park, S.K. (2007). Premenopausal factors influencing premature ovarian failure and early menopause. Maturitas, 58(1):19-30. doi:10.1016/j.

[10] Cochran, W.G. (1977). Sampling Techniques. $3^{\text {rd }}$.ed. New York: John Wiley and Sons.

[11] Copstead, L.C. \& Banasik, J.L. (2005). Pathophysiology. $3^{\text {rd }}$ edition. Philadelphia: Elsevier Inc. p822- 824.

[12] Dvornyk, V., Long, J.R., Liu, P.Y., Zhao, L.J., Shen, H., Recker, R., \& Deng, H.W. (2006). Predictive factors for age at menopause in Caucasian females. Maturitas, 54(1):19-26. doi:10.1016/j. Maturitas. 2005.08.005.

[13] Federal Republic of Nigeria [FRN] (2006) Population and Housing Census.

[14] Federal Republic of Nigeria, Official gazette, No. 24, vol. 94, 2007.

[15] Ferrand, F., Drauoi, D.M. \& Daniel, M.D. (2013). Comparative study of the quality of life associated with menopause in Tunisia and France. Menopause, 20(6):609-622. doi: 10.1097/GME.0b013e318278b0ce

[16] Freeman, E., \& Sherif, K. (2007). Prevalence of hot flushes and night sweats around the world: A systematic review. Climacteric: The Journal of The International Menopause Society, 10(3):197-214. doi:10.1080/13697130601181486

[17] Gold, E.B., Sternfeld, B., Kelsely, J.L., Brown, C., Mouton, C., \& Reame, N. (2000). Relation of demographic and lifestyle factors to symptoms in a multi-racial/ethnic population of women $40-55$ years of age. $A m J$ Epidemiol. 152:463 - 473.

[18] Hilditch, J.R., Lewis, J.E., Peter, A., van Maris, B., Ross, A., Franssen, E., Guyatt, G.H., Norton, P.G. \& Dunn, E. (1996). A Menopause-Specific Quality of Life Questionnaire: Development and Psychometric Properties. Maturitas, 24 (3): 161 - 175. (PubMed).

[19] Holms, N. (2005). Women's Health: A Guide to Health Promotion and Disorder Management. Philadelphia: 
Lippincott Williams \& Wilkins.

[20] Lawlor, D., Ebrahim, S., \& Smith, G. (2003). The association of socio-economic position across the life course and age at menopause: The British Women's Heart and Health Study. British Journal of Obstetrics \& Gynaecology, 110(12):1078-1087. doi:10.1111/j.1471 0528.2003.02519.x

[21] Lenz, E., Suppe, F., Gift, A., Pugh, C. \& Milligan, R (1995). Collaborative development of middle-range nursing theories: Towards a theory of unpleasant symptoms. Advances in Nursing Science, 17 (3): 1 - 13.

[22] London, M.L., Ladewig, P.W., Ball, J.W.,Binderler, R.C. (2007). Maternal and Child Nursing Care. $2^{\text {nd }}$ Edition. New Jersey: Pearson Prentice Hall. P. 84 - 99.

[23] Miller, B.F. \& Keane, C.B. (2003). Miller-Keane Encyclopedia and Dictionary of Medicine, Nursing and Allied Health. $7^{\text {th }}$ ed. U.S.A: Saunders. p1108-1110.

[24] Moilanen, J., Aalto, A.M., Hemminki, E., Aro, A.R., Raitanen, J. \& Luoto, R (2010). Prevalence of menopause symptoms and their association with lifestyle among Finnish middle-aged women. Maturitas 67 (4), $368-374$.

[25] Murphy, P., Phillips, G., Hall, A. \& Brooks, S. (2011). 2011 Women's Health Stats and Facts. The American Congress of Obstetricians and Gynecologists (ACOG). Washington, DC 20090-6920. Available at www.acog.org Accessed 23/03/2015.

[26] National Institute on Aging National Institutes of Health U.S. Department of Health and Human Services, (2013). Available at https://www.nia.nih.gov/health/.../menopause Accessed 19/10/2015.

[27] Nettina, S.M. (2010). Lippincott Manual of Nursing Practice. $9^{\text {th }}$ edition. Philadelphia: Lippincott Williams \& Wilkins. p.857-859.

[28] Nusrat, N. \& Nisar, A.S. (2009). Frequency of menopausal symptoms and their impact on the quality of life of women: A hospital based survey. Journal of Pakistan Medical Association. PMID 10687878 (PubMed indexed for MEDLINE).

[29] Qazi, R.A. (2006). Age, pattern of menopause, climacteric symptoms and associated problems among urban population of Hyderabad, Pakistan. J Coll Physicians Surg Pak. 16:700-703. Retrieved 17/10/2013.

[30] Rahman, S., Zainudin, S., \& Mun, V. (2010). Assessment of menopausal symptoms using modified Menopause Rating Scale (MRS) among middle age women in Kuching, Sarawak. Malaysia. Asia Pacific Family Medicine, 9(1). Retrieved 17/10/2013.

[31] Ricci, S.S. (2013). Essentials of Maternity, Newborn and Women's Health Nursing. $3^{\text {rd }}$ Ed. Philadelphia: Wolters Kluwer Health/Lippincott Williams \& Wilkins. International Ed. p.73, \& 122-129.

[32] Saka, M.J., Saka, A.O., Jimoh, A.A.G. \& Abdulraheem, I.S. (2012). Therapeutic Value of Multivitamin: Reducing Emerging Symptoms of Menopausal Women Helping As A Child Care Giver in Nigeria. African Journal of Pharmacy and Pharmacology, 6(2):92-97. DOI: 10.5897/AJPP11.338. Available at http://www.academicjournals.org/AJPP. (Retrieved 17 October, 2013).

[33] Schneider, H.P, Maclennan, A.H, Feeny, D. (2008). Assessment of Health-Related Quality of Life in Menopause and Aging. Climacteric, 11(2):93-107 (Retrieved 17 October, 2013).

[34] Sembulingam, K. \& Sembulingam, P. (2010). Essentials of Medical Physiology. $5^{\text {th }}$ edition. India: Jaypee Brothers Medical Publishers (P) Ltd. p.474 - 475.

[35] Smeltzer, S.C., Bare, B.G., Hinkle, J.L. \& Cheever, K.H. (2010). Brunner \& Sadarth's Textbook of MedicalSurgical Nursing. $12^{\text {th }}$ ed. Philadelphia: Lippincott Williams \& Wilkins. p.1414-1417.

[36] Syed, A.S.A, Lee, P.Y, Awi, I, Mallik, P.S \& Md Haizal, M.N. (2009). The Menopausal Experience Among Indigenous Women of Sarawak, Malaysia. Climacteric 12(6): 548 - 556. doi: 10.3109/13697130902919519. Retrieved 13/06/2013.

[37] Theroux, R. (2010). Women's decision making during the menopausal transition. Journal of The American Academy of Nurse Practitioners, 22:612-621. Retrieved 11/10/2013.

[38] Walsh, M. (2002). (ed). Watson's Clinical Nursing and Related Sciences. $6^{\text {th }}$ edition. Philadelphia: Elsevier Sciences Ltd. p. 804-806.

[39] World Health Organization. (1998). Development of the World Health Organization WHOQOL-BREF Quality of Life Assessment. The WHOQOL Group. Psychol Med.;28(3):551-558.

[40] Writing Group for the Women's Health Initiative. (2002). Risks and benefits of estrogen plus progestin in healthy postmenopausal women: Principal results from the women's health initiative randomized controlled trial. Journal of the American Medical Association, 228:321-333. Retrieved 17/10/2013. 